\title{
Mudanças na rotina profissional de mulheres jornalistas devido ao assédio sexual, verbal e moral ${ }^{1}$
}

\section{Changes in the professional routine of female journalists due to sexual, verbal and moral harassment}

\section{Cambios en la rutina professional de las mujeres periodistas debido al acoso sexual, verbal y moral}

\author{
Tatiane Gonsales Campagna \\ FIAM -FAAM - Centro Universitário - Brasil \\ Endereço currículo Plataforma Lattes: http://lattes.cnpq.br/2842144862644933 \\ E-mail: tatianegonsales@gmail.com \\ Letícia Paula Kutzke \\ FIAM-FAAM - Centro Universitário - Brasil \\ Endereço currículo Plataforma Lattes: http://lattes.cnpq.br/6586733918155247
}

\begin{abstract}
Resumo: As mudanças ocorridas no mercado de trabalho, principalmente oriundas do pós-fordismo, mudaram as relações de trabalho. Com isso, episódios de assédio ocorridos nas rotinas de trabalho passam a ganhar notoriedade em estudos e noticiários - e com as mulheres jornalistas não é diferente, desencadeando em campanhas como "\#jornalistascontraoassedio". Assim, fora feita pesquisa com 181 mulheres jornalistas a fim de compreender se há algum tipo de alteração no exercício de suas profissões após sofrerem assédio, seja este verbal, moral ou sexual. Como resultado, tem-se que a maioria sofreu assédio e, apesar de retratarem, de forma objetiva em questionário, que tal fato em nada modificou o modo de fazerem jornalismo, seus depoimentos espontâneos e anônimos mostram mudanças de comportamento, setores e até de carreira.
\end{abstract}

Palavras-chave: Jornalismo. Mulheres jornalistas. Assédio. Trabalho.

Summary: Changes in the job market, mainly from post-Fordism, have changed labor relations. Therefore, harassment episodes that occur in work routines are gaining notoriety in studies and news - and with women journalists it isn't different, triggering in campaigns such as "\#journalists against harassment". Thus, research had been conducted with 181 women journalists to understand if there is any change in the exercise of their professions after suffering harassment, be it verbal, moral or sexual. As a result, most have been harassed and, despite objectively portraying in a questionnaire, that this has not changed the way they do journalism, their spontaneous and anonymous statements show behavioral changes, sectors and even career paths.

Keywords: Journalism. Women journalists. Harassment. Job. 
Resumen: Los cambios en el mercado laboral, principalmente desde el postfordismo, han cambiado las relaciones laborales. Como resultado, los episodios de acoso que ocurren en las rutinas de trabajo están ganando notoriedad en estudios y noticias, y con las mujeres periodistas no es diferente, lo que desencadena en campañas como "\#periodistas contra el acoso". Por lo tanto, se realizaron investigaciones con 181 mujeres periodistas para comprender si hay algún cambio en el ejercicio de sus profesiones después de sufrir acoso, ya sea verbal, moral o sexual. Como resultado, la mayoría ha sido acosada y, a pesar de retratar objetivamente en un cuestionario, que esto no ha cambiado la forma en que hacen el periodismo, sus declaraciones espontáneas y anónimas muestran cambios de comportamiento, sectores e incluso trayectorias profesionales.

Palabras llave: Periodismo. Mujeres periodistas. Acoso. Trabajo.

\section{Introdução}

Dois tiros, um nas costas e outro na cabeça, saídos do revólver de seu ex-namorado e chefe de redação do jornal $O$ Estado de S. Paulo, Antônio Pimenta Neves. Assim a jornalista Sandra Gomide foi assassinada, em 2000. Pimenta revelou ser autor do crime e indiciado por homicídio doloso, quando há a intenção de matar. Conforme testemunhas, desde que o casal começou a namorar, quando atuavam no Gazeta Mercantil, Pimenta tinha um comportamento agressivo e abusivo com Sandra. Porém, somente 11 anos após o ocorrido, o réu foi preso ao se entregar à polícia. Neste tempo, recursos, reduções de pena e fugas mantiveram o jornalista fora da prisão.

Apesar do caso ter sido chocante à época, não é uma ocorrência isolada de assédio cometido a mulheres jornalistas. Em 2016, uma repórter do portal $i G$ foi demitida duas semanas após denúncia do assédio sofrido por MC Biel durante entrevista sobre seu mais recente álbum. A repórter o acusou ao dizer "menina, se eu te pego, eu te quebro no meio" caso tivessem relações sexuais Em repúdio à demissão e ao assédio cometidos, jornalistas se mobilizaram à criação da campanha "Jornalistas contra o assédio", em 20 de junho de 2016. Fora lançado um vídeo com depoimentos de mulheres atuantes no jornalismo, em que relatam investidas de cunho sexual, verbal e moral por colegas e entrevistados devido ao gênero. A campanha rendeu ainda a hashtag "\#jornalistascontraoassedio", que abriu espaço para que demais profissionais da área reunissem suas histórias nas redes sociais, como Twitter e Facebook, de maneira a trazer maior visibilidade à causa. 
Já em 2018, 52 mulheres que atuam com jornalismo esportivo divulgaram a campanha "Deixa Ela Trabalhar" a fim de elucidar situações de assédio vivenciadas durante a jornada de trabalho. O vídeo do projeto foi disponibilizado nas redes sociais e também antes da transmissão da final da Taça Rio, no estádio do Maracanã. Segundo descrição no site oficial da campanha, o objetivo do grupo é lutar contra episódios de assédio e agressões a jornalistas em estádios, redações e até mesmo por colegas de profissão. Dentre as profissionais que relatam seus depoimentos, estão Fernanda Gentil, Cris Dias, Aline Nastari e Ana Thais Matos.

A iniciativa foi criada após a jornalista Renata de Medeiros, da Rádio Gaúcha, ser xingada e agredida por um torcedor do Sport Club Internacional enquanto cobria o clássico entre o time e o Grêmio no estádio Beira-Rio: "sai daqui, p*".

Frente à necessidade de campanhas a mobilizar o público sobre o assédio sofrido no exercício profissional por mulheres jornalistas, sendo estas, especialmente entre $20 \mathrm{e}$ 29 anos, a maioria na profissão exercida no Brasil (58\%) segundo Censo 2010, este artigo pretende responder à seguinte pergunta-problema: como o assédio afeta a rotina de trabalho de mulheres jornalistas?

Assim, foram obtidas 181 respostas anônimas ${ }^{2}$ de mulheres jornalistas por meio de amostragem por conveniência. A amostragem é fruto de pesquisa quantitativa realizada pelas autoras do artigo entre 23 a 31 de maio de 2018, via questionário on-line em grupos de redes sociais voltados a jornalistas. Juntamente à estratégia, a última questão disponibilizada e nãoobrigatória era um espaço livre para que as participantes deixassem um depoimento ${ }^{3}$, caso assim desejassem. Esta parte, de cunho qualitativo, contou com 31 respostas.

O objetivo principal da execução do questionário foi captar informações de mulheres jornalistas sobre a prática do assédio, de forma a entender os autores deste tipo de ato; como se apresenta; se exerce influência em suas rotinas profissionais; e, caso exerce, como essa influência se manifesta. Fora realizada, também, uma análise teórica embasada em pesquisas já divulgadas, relacionadas a assédios a jornalistas, bem como levantamento histórico da figura feminina no mercado de trabalho e nas redações, a fim de compreender o espaço de fala e de exercício da profissão à mulher jornalista.

\section{Assédio no trabalho: discussão nova, fenômeno velho}

O trabalho é um conjunto de atividades organizado pelo homem e aplicado sobre a natureza, a fim de assegurar sua subsistência (PINTO, 2013, p. 15). Desde os primórdios, o 
trabalho não é considerado, pela maioria dos indivíduos, como um ato desejável - o que justifica a origem da palavra, derivada de Tripalium, um antigo instrumento de tortura.

Contudo, é a partir de 1970 que surge um novo modo de ser do trabalho: o Toyotismo, também conhecido como Pós-Fordismo. Sua metodologia se baseava em mãode-obra altamente capacitada para agregar diversas atividades. Era preciso reduzir ou até mesmo eliminar o trabalho improdutivo, que não criava capital - como consequência, há a intensificação das condições de exploração da força de trabalho (PINTO, 2013).

As demandas do Pós-Fordismo tiveram impactos diretos no mercado de trabalho, presentes até os dias atuais (FONSECA, 2008). Neste novo regime prevalecem as ideias de flexibilização; desregulamentação de direitos trabalhistas; processo produtivo flexível, em que diferentes tarefas são operadas simultaneamente; e medição de desempenho a partir da disciplina de entregas (PINTO, 2013; SOUZA, 2017).

O jornalismo não ficou de fora: várias mudanças advindas do Pós-Fordismo foram implantadas nos veículos de comunicação visando uma maior produtividade e menores gastos com pessoal. Demissões maciças, fechamentos e incertezas nos empregos se tornaram comuns em veículos de comunicação, particularmente na indústria impressa (WAISBORD, 2017, p. 206).

Assim, o contexto do trabalho volta-se ao controle de empregadores, que visam ao lucro em detrimento do bem-estar de seus empregados - seja este bem-estar mental, emocional ou físico (HELOANI, 2004). É nesta constante e deliberada desqualificação da vítima, que se vê fragilizada e se remetendo a condições de flexibilização, terceirização e exploração do trabalho, que o assédio ganha forças.

O assédio moral é uma conduta abusiva, frequente, intencional e repetitiva no ambiente de trabalho, em que o assediador humilha, constrange e desqualifica um indivíduo ou grupo a fim de gerir e controlar os processos de trabalho (HIRIGOYEN, Marie-France; 2008).

Não há legislação específica sobre o assédio moral, mas tramitam no Congresso Nacional propostas como o Projeto de Lei 4742/01, que visa incluir o assédio moral no ambiente de trabalho como crime no Código Penal. Atualmente a conduta costuma ser introduzida, segundo o Código Penal brasileiro, como crime contra a honra, artigos 139 (Difamação) e 140 (Injúria); crime de periclitação da vida e da saúde, artigo 136 (Maustratos); ou crime contra liberdade individual, artigo 146 (Constrangimento ilegal). 
Já o assédio sexual é um tipo agravado de assédio moral, considerado crime e com detenção de até dois anos após a comprovação. Conforme o artigo 216 do Código Penal, o assédio sexual é caracterizado por constrangimentos e ameaças com a finalidade de obter favores sexuais feita por alguém normalmente de posição superior à vítima.

Por sua vez, o assédio verbal, de acordo com o artigo 61 da Lei das Contravenções Penais n. 3.688/41, ocorre quando alguém expõe dizeres desagradáveis, invasivos ou ameaçadores à vítima. Até mesmo cantada, quando deixa a vítima encabulada, é um assédio verbal e pode gerar constrangimento à vítima, mesmo sendo considerado como ato de potencial ofensivo baixo pela legislação.

O assédio no ambiente de trabalho, seja moral, sexual ou verbal, é considerado um dos principais estressores das organizações públicas e privadas (SOARES; OLIVEIRA, 2012), resultando em altos níveis de depressão, ansiedade, dor de cabeça, isolamento social, doenças cardiovasculares, queda de autoestima e insatisfação profissional (HANSEN, 2006).

Apesar de estar em pauta nos últimos anos, o fenômeno do assédio é tão antigo quanto a própria existência do trabalho como atividade laboral (HELOANI, 2004). Porém, se antes o assédio se dava basicamente do patrono ao peão, dos colonizadores aos escravos, hoje abrange as mais variadas profissões - a incluir os profissionais de imprensa.

O exercício de mais de um emprego é realidade a um terço dos jornalistas (MICK, 2015), o que demonstra abuso em relação a direitos trabalhistas. Jornadas prolongadas, além das 40 horas semanais estabelecidas pela Consolidação das Leis Trabalhistas (CLT) - prolongando-se geralmente de 41 a 60 horas. O acúmulo de funções e enxugamento da estrutura de redações fazem com que permaneçam em seus empregos atuais, por mais que, para isso, tenham de reduzir o tempo dedicado às horas de sono e lazer para, em contrapartida, aumentar o expediente dedicado ao jornalismo (HELOANI, 2006). Como resultado, dizem que "aprenderam a suportar" o estresse vivenciado pela exploração do trabalho e que "se sentem fracassos" em relação à saúde.

O sofrimento também se faz presente nos estudos de Reimberg (2015), que analisou a relação do assédio moral ao trabalho de 21 jornalistas. Aos entrevistados, o termo "sofrimento" associa-se à precarização do trabalho, além de desgaste físico e mental. Ainda, para $76,2 \%$ dos respondentes, a palavra aparece interligada ao assédio moral, resultante de exposições humilhantes, constrangedoras e repetitivas por outros profissionais durante a jornada de trabalho. Destes que relataram assédio, todos são jornalistas mulheres. Heloani 
(2004) afirma que, frente a esta figura de poder do empregador, cujo foco é a neutralização da vítima (uma vez que essa apenas aceita o que lhe é proposto e não rebate aos abusos sofridos), no Brasil as mulheres se destacam como aquelas que mais sofrem assédio no ambiente de trabalho jornalístico.

\section{Presença feminina em redações}

No jornalismo, não há consenso entre estudiosos sobre a primeira mulher a atuar como profissional da área no Brasil. Apesar disso, indícios ressaltam décadas de disparidade em relação ao lançamento do primeiro veículo midiático registrado - o Gazeta do Rio de Janeiro, em 10 de setembro de 1808. Alguns pesquisadores afirmam que Nísia Floresta (codinome de Dionísia Pinto Lisboa) poderia ser, além de primeira feminista do país por empoderar mulheres a se tornarem acadêmicas, considerada a pioneira no jornalismo brasileiro, uma vez que escrevia artigos em jornais locais e fundou o chamado Espelho das Brasileiras em 1831, jornal destinado a mulheres pernambucanas (ALBERTON, 2010). Nísia usava a escrita para acender discussões sobre os preconceitos sofridos pelas mulheres na sociedade patriarcal brasileira, reivindicando educação, igualdade e respeito de gênero.

Entretanto, devido à ausência de registros de tal veículo impresso, demais historiadores dão à Joana Paula Manso de Rocha o título de primeira jornalista brasileira, ao ser editora e redatora do Jornal das Senhoras. Lançado em $1^{\circ}$ de janeiro de 1852, o periódico destacou-se como impresso destinado e escrito por mulheres em tempos cuja presença feminina em redações era praticamente nula.

Diante das I e II Guerras Mundiais (1914-1918 e 1939-1945), muitos homens foram mutilados ou impossibilitados de retornar à rotina profissional, o que fez com que a presença feminina se fortalecesse especialmente em fábricas, com o desenvolvimento tecnológico das máquinas (PRIORE; BASSANEZI, 1997). No Brasil, enquanto homens serviam às lutas em trincheiras durante a Revolução Constitucionalista de 1932, mulheres desempenhavam tarefas como cozinheiras, enfermeiras, costureiras e operadoras em indústrias bélicas e de logística. Outras assumiram até posições na batalha, como auxiliares de soldados e combatentes. Leis foram instauradas na tentativa de igualar direitos de gêneros, como a Constituição de 1932, que estabelece que: 
comerciais, públicos ou particulares, é vedado desde 22 horas até 5 horas. [...] Art. $7^{\circ} \mathrm{Em}$ todos os estabelecimentos industriais e comerciais, públicos ou particulares, é proibido o trabalho à mulher grávida, durante um período de quatro semanas, antes do parto, e quatro semanas depois.

Segundo o IBGE, a população brasileira hoje concentra 4,6 milhões de mulheres a mais do que homens. De forma a acompanhar esse registro, o perfil do jornalista brasileiro também aponta que a maior parcela dos profissionais são mulheres. Contudo, apesar das mulheres serem maioria, terem conquistado o direito a voto, leis que buscam o equilíbrio entre homens e mulheres no ramo profissional, oportunidades de ingresso na educação e no mercado de trabalho, as diferenças no tratamento ao gênero nas redações ainda são notórias.

Há 65,4\% mais homens do que mulheres em cargos de poder (editores, coordenadores, diretores) em veículos jornalísticos no Brasil. Esta é uma das razões pelas quais 53,4\% das jornalistas creem que homens têm maior capacidade de progredir em suas carreiras do que elas. Além disso, mais de $86 \%$ das mulheres jornalistas admitiram já ter passado por no mínimo uma situação de discriminação de gênero no ambiente de trabalho. Ou seja, por situações listadas como distribuição de tarefas de modo desigual entre homens e mulheres; diferenciação para obtenção de promoção ou melhor oportunidade de trabalho; aumento de benefícios ou salário; e extensão de expediente ou escalas de horários de plantão. Os dados foram divulgados no relatório "Mulheres no jornalismo brasileiro", idealizado pela Associação Brasileira de Jornalismo Investigativo (ABRAJI) em 2017.

Além dessas ocorrências de abuso de poder e distinção de tratamento por gênero, o assédio se faz presente na vida das entrevistadas. Elas relataram, como exemplo, que sofrem pressão para que não engravidem - o que impediria o usufruto de licença maternidade ou de possíveis ausências no expediente devido a incidentes pessoais relacionados a filhos. Ainda, houve relatos de assédio sexual: 70,4\% das participantes receberam cantadas de cunho sexual durante o exercício da profissão que as deixaram desconfortáveis; e $70 \%$ presenciaram ou tomaram conhecimento de alguma colega jornalista sendo assediada em ambiente de trabalho por colega ou superiores.

Assim, firmam-se as evidências em estudos de que o assédio é vivenciado pela maioria das mulheres jornalistas. Mas, afinal, como esses acontecimentos impactam, direta ou indiretamente, a rotina profissional dessas profissionais assediadas ou que tiveram a informação de uma colega que veio a sofrer assédio? 


\section{Frutos do assédio}

Em nossa pesquisa, partimos do pressuposto de que todas as respostas foram cedidas por mulheres formadas em jornalismo e que atuam na área. Juntamente ao link do questionário, foi divulgado um breve texto explicativo: apesar de não ser uma exigência às participantes, a pesquisa fora focada em profissionais já graduadas a fim da formalização do status de jornalista profissional.

Quando questionadas sobre idade, a maior parcela das respondentes afirma ter entre 26 e 30 anos (29\%), seguida daquelas entre 20 e 25 anos (25\%). Assim, os dados comprovam o que o Censo 2010 e a pesquisa de Mick também apontaram: a maioria das jornalistas são jovens, de até 30 anos.

O fator da idade também surgiu dentre os relatos, apontando casos de assédio que ocorrem justamente pela ideia da jovialidade associada à falta de expertise.

\footnotetext{
Uma chefe minha (eu estava no $1^{\circ}$ ano da facul) gritava perguntando se eu era burra por não saber fazer algumas coisas, por falta de experiência. Me fez duvidar de todas as minhas habilidades, perdi confiança e me demiti pouco tempo depois (ANÔNIMA 1).
}

Este tipo de assédio coloca a vítima em uma situação de fragilização diante de alguém com cargo superior ou com uma carreira já mais extensa. A figura de chefe aparece tanto como responsável pelo assédio cometido, como também correlacionada a casos de omissão diante de um assédio presenciado.

O tempo de experiência das jornalistas também reflete o fortalecimento de jovens nos veículos midiáticos. A maioria tem entre 5 e 10 anos de carreira na área (33\%). O segundo maior grupo, com percentual bastante próximo, tem menos de 5 anos de experiência (32\%).

A partir da terceira questão, entra-se no tema assédio: "Já sofreu assédio no exercício da profissão (seja no espaço de trabalho, em coletivas, entrevistas, etc.)?”. O resultado referente a mulheres jornalistas que apontaram terem sofrido assédio é bastante expressivo: 86,7\%. O mesmo ocorre nos estudos de Reimberg e da ABRAJI, executados em 2015 e 2017, respectivamente, sobre assédio durante a rotina de trabalho de jornalistas, cuja maioria das entrevistadas relataram serem vítimas de assédio. Por outro lado, em nossa pesquisa 10,5\% das participantes disseram que não sofreram assédio.

Ainda, 2,8\% não souberam informar se já sofreram assédio. Apesar do número ser bastante inferior quando comparado aos resultados das demais opções, as próprias respondentes discutiram sobre possíveis comportamentos internalizados por mulheres jornalistas a respeito do assédio. Mesmo que as participantes não tivessem acesso aos 
resultados do questionário até a escrita deste presente artigo, foram obtidos comentários que tentam justificar o porquê mulheres jornalistas poderiam não admitir ou mesmo identificar uma situação de assédio: "várias formas de assédio estão tão naturalizadas, consideradas normais (faz parte, é assim mesmo), que muitas vezes não entendemos aquele gesto, ação ou comentário como assédio" (ANÔNIMA 3). Diante deste cenário, algumas das mulheres jornalistas apontaram como batalham, em seus ambientes de trabalho, contra o assédio e, para isso, efetuam ações de conscientização.

Trata-se de uma série de ações degradantes dia após dia, são "pequenas" ações e comentários e a gente mesma acaba tornando isso normal, mas não pode ser. Recentemente, onde trabalho, fizemos uma campanha contra o assédio e isso causou um furor gigantesco entre os homens. Assustaram-se, tentaram desmoralizar o movimento, diminuí-lo, tivemos que conversar individualmente com todos para que a situação começasse a se normalizar. Agora, parece até ter melhorado um pouco. Mas é uma luta diária (ANÔNIMA 4).

O assédio verbal, feito por cantadas, ameaças e ofensas, foi o mais vivenciado pelas entrevistadas ${ }^{4}$ (aproximadamente $80 \%$ ). Em seguida, o assédio moral aparece com $51 \%$; o sexual, com 11, 6\%. Este último, que visa objetivos sexuais por meio de ameaça, insinuação de ameaça ou hostilidade, teve o mesmo percentual de resposta diante daquelas que apontaram não terem sofrido nenhum tipo de assédio.

Conforme abordado anteriormente, chefes e superiores aparecem como autores de assédio - sendo, até mesmo, os principais responsáveis pelas ocorrências vivenciadas pelas mulheres jornalistas de nossa pesquisa, com aproximadamente 55\% das respostas diante da questão "Caso tenha sofrido assédio(s), por quem foi feito?". Além dos casos de assédio verbal e moral, nos depoimentos as pessoas de posições hierárquicas acima daquelas exercidas pelas jornalistas entrevistadas também foram responsáveis pela maioria dos assédios sexuais cometidos.

Trabalhei para uma revista, e o dono me pediu literalmente sexo oral na volta da cobertura de uma inauguração de uma grande empresa no norte do Paraná (ANÔNIMA 5).

Casos em que colegas de trabalho e fontes fragilizaram mulheres jornalistas por meio de assédio tiveram percentagens próximas - com $48 \%$ e $44 \%$, respectivamente. Cerca de $3 \%$ preferiu não responder.

Ao pedir uma breve entrevista para o jornal, o lutador disse "ah, mas não pode ser à noite no meu quarto de hotel?". Minhas amigas e eu ficamos extremamente incomodadas e chateadas. Novamente repeti que não era necessário e que se não fosse ali não seria em lugar nenhum. Por fim, o assessor dele pediu para que ele falasse ali mesmo para evitar problemas. Foi minha primeira experiencia 
profissional e fui assediada. É algo que me fez pensar bastante sobre minha carreira (ANÔNIMA 6).

Os casos de assédio, mesmo que cometidos por profissionais externos ao ambiente de trabalho diário - como clientes, que não convivem diariamente no mesmo espaço de redação que os jornalistas, por exemplo - resultam em temores por parte das vítimas. Esses temores por muitas vezes estão ligados a novas tentativas de assédio pela mesma pessoa - ou que novos casos viessem a ocorrer, mesmo que por demais indivíduos. Porém, em suma maioria, tais temores estão correlacionados com o medo de ações possíveis de serem tomadas por parte do(a) assediador(a) como uma espécie de vingança ou desmoralização da vítima, prejudicando-a no exercício de sua profissão. Um dos medos mais presentes pelas mulheres jornalistas, portanto, é a de que a denúncia de assédio resulte em suas próprias demissões.

\begin{abstract}
Uma vez um colega quis sair comigo e eu disse que não. Ele continuava insistindo, cada vez mais enfaticamente e eu continuava a negar. Ele simplesmente não entendia que não ia rolar nada. E começou a me perseguir também fora do trabalho. Fiquei com muito medo de ser atacada por ele, mas também tive medo que, por vingança, ele tentasse me prejudicar no trabalho e nunca disse nada a ninguém (ANÔNIMA 7).
\end{abstract}

Quando questionadas "O assédio sofrido desencadeou algum problema de saúde física a você?", mais de 64\% afirmou que não. Ressalta-se aqui que a quantidade de mulheres jornalistas que não souberam informar (12,2\%) se tiveram sequelas físicas diante dos casos de assédio sofridos é maior do que daquelas que afirmaram que tiveram problemas de saúde física ou que não sofreram assédio (ambos resultados com 11,6\%). Entre os depoimentos, somente um apontou danos físicos como sequência do ato:

\footnotetext{
Sofri inúmeros assédios morais dos dois donos da agência e de uma diretora de comunicação. Gritos, ameaças, terror, situações vexatórias na frente da equipe e com toda a equipe eram frequentes. Tive uma crise de ansiedade uma vez na agência e precisei ir para o pronto-socorro com sintomas semelhantes a um infarto. Foram quase dois anos assim (ANÔNIMA 8).
}

Em relação ao desencadeamento de influências negativas à saúde mental, o número de participantes que não sabem responder é ainda maior ao comparar com o questionamento acerca da saúde física: $15,5 \%$. O percentual de jornalistas que afirmaram não terem tido problemas relacionados à mentalidade após os casos de assédio cai (47\%). Portanto, o de respostas favoráveis a sequelas mentais aumenta (26\%).

O depoimento da anônima 9 demonstra que, antes de ter sintomas de parada cardíaca, o que se atribui como uma sequela física, a jornalista aponta ter sofrido uma 
crise de ansiedade por conta dos constantes assédios cometidos por superiores. Desta forma, o dano físico segue o dano mental.

Ainda, os retratos de problemas mentais têm forte ligação com estresse e ansiedade:

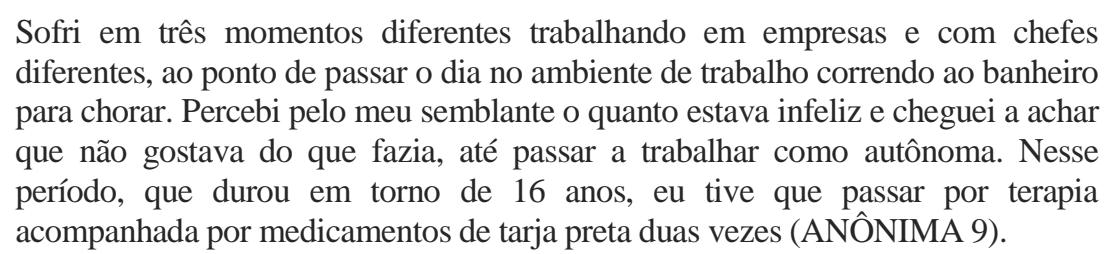

A parte referente às perguntas objetivas se encerra, então, com o questionamento que se pretende desvendar neste artigo: "O assédio atrapalhou sua rotina de trabalho quando comparada com antes do ocorrido?". Mais da metade (quase 54\%) das respondentes afirmaram que sim.

São mudanças sutis, a gente passa a cuidar mais a roupa que usa (para não ser mal interpretada), já troquei de rota pra não passar em frente da sala do assediador, mudança de postura, parece que sempre precisamos ser ainda mais profissionais para não dar margem para que a relação que era de trabalho fuja deste contexto (ANÔNIMA 10).

Nos depoimentos aparecem casos de demissão, atraso de salário, troca de departamento e perda de benefícios como ações tomadas pela empresa para abafar os casos de assédio.

$\mathrm{Na}$ época eu era assessora de gabinete e imprensa de um secretário da prefeitura. Ele nos tratava mal (a mim e a outra assessora) diariamente com assédio moral e sexual - por palavras. Até que um dia me agarrou à força. Fui à chefia de gabinete do prefeito com a questão. Me trocaram de secretaria. Quando o assunto chegou ao prefeito, fui exonerada. Era cargo de confiança. (ANÔNIMA 11).

Menos de $1 / 2$ dessa percentagem foi equivalente às respostas relacionadas ao fato de que o assédio não interferiu no exercício de suas profissões (23\%).

Contudo, há a presença de contradição ao analisar respostas de forma individual das participantes. Percebe-se que muitas das mulheres jornalistas assumiram o posicionamento de que as ocorrências de assédio não alteraram suas rotinas produtivas; porém, em seus relatos feitos de forma espontânea apontam mudanças de comportamentos no ambiente de trabalho.

Passei a me policiar para não ficar sozinha no mesmo ambiente que a pessoa. Foi muito difícil de lidar e nunca me senti à vontade de compartilhar essas histórias com ninguém ou denunciar. Infelizmente eu dependia do meu emprego e não poderia correr o risco de uma demissão (ANÔNIMA 12). 
Esta contradição também aparece se somente analisarmos os depoimentos. Alguns chegam a apontar que nada foi alterado em suas rotinas; porém, pediram demissão e abriram o próprio negócio.

\footnotetext{
Não atrapalhou em nada minha rotina. Pois, após os ânimos se acalmarem, sentei com meu superior e tivemos uma conversa franca e esclarecedora. Pedi demissão, abri minha empresa e não preciso passar por essa situação novamente (ANÔNIMA 13).
}

Houve também aquelas que não sofreram assédio e não presenciaram situações do tipo que alterassem suas rotinas (9,5\%); e as que não foram vítimas de casos do tipo, mas tomaram conhecimento de uma colega que foi assediada e perceberam que isso modificou o dia a dia (2,8\%). Cerca de 5\% não soube informar e $1 \%$ preferiu não responder.

Observa-se que o empreendedorismo e a busca por diferentes áreas de atuação são tidos como soluções plausíveis às mulheres jornalistas entrevistadas para escapar de situações de assédio ou não serem, novamente, vítimas dessas ocorrências.

Sofri assédio moral e sexual que foram realizados por colegas de trabalho e chefia. Estou procurando novos meios e outros ramos (profissão) como forma de sobrevivência (ANÔNIMA 14).

Parte dessa busca por alternativas fora do ambiente atual de trabalho provém da identificação, mas aceitação, de que assédios fazem parte da realidade - especialmente no meio jornalístico.

O jornalismo hoje tem muitas mulheres, mas continua sendo um meio machista. Por isso, agora que tenho a minha empresa, procuro só contratar pessoas do sexo feminino (ANÔNIMA 15).

\section{Conclusões}

O jornalismo hoje é tomado por mulheres jovens, com até 30 anos e em início de carreira profissional - com até 10 anos de experiência no âmbito jornalístico. Chama a atenção o fato de que este público, mesmo sendo majoritário, sinalize que já foram vítimas de assédio, seja este verbal, moral ou sexual. Este dado é presente tanto na pesquisa realizada em virtude do presente artigo, que contou com 181 entrevistadas anônimas via questionário on-line em maio de 2018 - destas, cerca de $87 \%$ diz ter sofrido assédio -, como também nas análises realizadas por Reimberg em 2015 e pela ABRAJI em 2017.

A maioria dos assédios são cometidos por chefes ou indivíduos com cargos superiores aos das profissionais participantes $(54,7 \%)$ e predominantemente homens. Isso DOI: http://dx.doi.org/ 10.14393/par-v4n2-2019-50618 Paradoxos, Uberlândia, v. 4, n. 2, p. 38-52, jul./dez. 2019 | 49 
emerge nos relatos das respondentes, que expuseram situações cometidas por tais colaboradores durante suas rotinas de trabalho. Esta informação vai de encontro ao que já fora relatado nos estudos anteriores, de que figuras masculinas são maioria em posições de chefias no jornalismo e são os que mais assediam as companheiras de profissão.

Os assédios não vieram a desencadear problemas físicos ou mentais à maioria das participantes da pesquisa aplicada. Em contrapartida, é notável um enorme nível de estresse e sofrimento (REIMBERG, 2015) durante e após o assédio, sendo perceptível relatos associados à perda de autonomia (mudança de setor ou de clientes) e expressivo desconforto (foram usadas expressões como "estava infeliz", "me deixou em pânico", “terror", "medo", “extremamente incomodadas", “chateadas", "algo desconfortável”).

Diante do problema que este artigo buscou responder, conclui-se que, apesar das respostas objetivas demonstrarem que a maioria das jornalistas não tiveram alterações no exercício da profissão após presenciarem situações de assédio, seus depoimentos escritos de forma espontânea e anônima expressam o contrário. Há constantes referências sobre alterações de comportamentos, como desviar olhares e caminhos ao assediador, repensar nas vestimentas a serem usadas; pedidos de demissão; e até mesmo buscas por novos mercados de atuação profissional, seja como empregada ou como dona da própria organização.

Além disso, mesmo que as mulheres jornalistas em suma maioria sejam vítimas de assédio, sendo este expressado das mais diferentes formas, grande parte das entrevistadas optaram por não denunciar o caso. Este medo torna-se ainda mais presente a partir de 1970, em que o período pós-fordista rege um contexto de trabalho que se volta ao controle dos empregadores, que optam pelo capital ao invés do bem-estar mental, emocional e físico do empregado. As jornalistas se veem imersas em um mercado regido por altos índices de desemprego; enfraquecimento de direitos trabalhistas; precarização; flexibilização. Portanto, o medo de perder a posição atual relativa ao emprego faz com que muitas ainda se submetam a aceitar assédios. 


\section{Referências}

\#DEIXAELATRABALHAR: jornalistas lançam manifesto em defesa do trabalho das mulheres no esporte. GloboEsporte.com, 25 mar. 2018. Disponível em: $<$ https://globoesporte.globo.com/sp/futebol/noticia/deixaelatrabalhar-jornalistaslancammanifesto-em-defesa-do-trabalho-das-mulheres-no-esporte.ghtml>. Acesso em: 03 jul. 2018. https://doi.org/10.22409/tn.4i4.p4605

$2^{a}$ TURMA determina imediata execução da sentença contra jornalista Pimenta Neves.

Supremo Tribunal Federal. Disponível em:
<http://www.stf.jus.br/portal/cms/verNoticiaDetalhe.asp?idConteudo=18 0297>. Acesso em: 03 jul. 2018.

ALBERTON, Mirele; CASTRO, Amanda Mota Angelo; EGGERT, Edla. Nísia Floresta, a mulher que ousou desafiar sua época: Feminismo e Educação. VIII Congresso Iberoamericano de Ciência, Tecnologia e Gênero. UTFPR, Curitiba, 2010.

ÁUDIO em que MC Biel assedia repórter em entrevista é vazado e cantor é cortado de levar tocha olímpica. Folha de S. Paulo. Disponível em: $<$ https://f5.folha.uol.com.br/celebridades/2016/06/10002420-audio-em-que-mc-bielassedia-reporter-em-entrevista-e-vazado-cantor-e-cortado-de-levar-tochaolimpica.shtml>. Acesso em: 01 jun. 2018. https://doi.org/10.32334/oqnfp.2019n44a701

BRASIL. Decreto n. 21.417, de 17 maio de 1932. Regula as condições do trabalho das mulheres nos estabelecimentos industriais e comerciais. Disponível em: <http://www2.camara.leg.br/legin/fed/decret/1930-1939/decreto-21417-17-maio1932559563-publicacaooriginal-81852-pe.html>. Acesso em: 02 jun. 2018.

CENSO 2010. IBGE. Disponível em: <https://censo2010.ibge.gov.br/>. Acesso em: 03 jul. 2018.

HANSEN, A. M. et al. Bullying at work, health outcomes and physiological stress response. Journal of Psychosomatic Research, v. 60, n. 1, p. 63-72, 2006. https://doi.org/10.1016/j.jpsychores.2005.06.078

HELOANI, Roberto. Assédio moral: um ensaio sobre a expropriação da dignidade do trabalho. RAE-eletrônica, v. 3, n. 1, 2004. https://doi.org/10.1590/s1676$\underline{56482004000100013}$

HELOANI, Roberto. O trabalho do jornalista: estresse e qualidade de vida. Red de Revistas Científicas de América Latina y el Caribe, España y Portugal, v. 12, n. 22, p. 171-198, 2006.

HIRIGOYEN, Marie-France. Assédio Moral: a Violência Perversa no Cotidiano. Rio de Janeiro: Bertrand Brasil, 2002.

MICK, Jacques. Trabalho jornalístico e convergência digital no Brasil: um mapeamento de novas funções e atividades. Revista Pauta Geral-Estudos em Jornalismo. Ponta Grossa, v. 2, p. 13-17, 2015. https://doi.org/10.18661/2318-857x/pauta.geral.v2n1p15-37 
MULHERES no jornalismo brasileiro. Mulheres No Jornalismo Brasileiro. Disponível em: <www.mulheresnojornalismo.org.br/12901_GN_relatorioV4.pdf>. Acesso em: 30 jun. 2018.

O JORNAL das Senhoras. Biblioteca Nacional Digital, 1 jan. 1852. Disponível em: <http://objdigital.bn.br/acervo_digital/div_periodicos/per700096/1852/per700096_1852 _01.pdf>. Acesso em: 03 jun. 2018.

PINTO, Geraldo Augusto. A organização do trabalho no século XX: taylorismo, fordismo e toyotismo. São Paulo: Expressão Popular, 2013.

PRIORE, Mary Del e BASSANEZI, Carla. História das mulheres no Brasil. 2. ed. São Paulo: Contexto, 1997. https://doi.org/10.1590/s0104-71831997000300020

REIMBERG, Cristiane Oliveira. Quando o trabalho do jornalista é cenário para o assédio moral. XXXVIII Congresso Brasileiro de Ciências da Comunicação. Rio de Janeiro, 2015.

PROJEÇÃO da população. IBGE. Disponível em: <https://www.ibge.gov.br/apps/populacao/projecao/>. Acesso em: 14 jun. 2018.

Data Recebimento: 20/09/2019

Data Aprovação: 11/2019

\footnotetext{
${ }^{1}$ GONSALES, Tatiane. "Mudanças na rotina profissional de mulheres jornalistas devido ao assédio sexual, verbal e moral". In: $16^{\circ}$ SBPJOR - Encontro Nacional de Pesquisadores em Jornalismo, 2018, São Paulo. Anais eletrônicos do $16^{\circ}$ Encontro da SBPJor. São Paulo: SBPJor, 2018. Disponível em: <http://sbpjor. org.br/congresso/index.php/sbpjor/sbpjor2018/paper/viewFile/1611/800>. Acesso em: 20 set. 2019.

${ }^{2} \mathrm{O}$ anonimato foi preservado durante toda a pesquisa para proteção de identidade das entrevistadas.

${ }^{3}$ Texto referente à última parte do questionário: "Se desejar e se sentir à vontade, deixe aqui seu depoimento a respeito do assunto. Use esse espaço anônimo caso queira contar do ocorrido; o que isso desencadeou a você ou à sua rotina como jornalista; sua opinião a respeito; ou qualquer outro ponto que queira comentar".

${ }^{4}$ Fora perguntado "Se você já sofreu assédio, como você o classifica? (Você pode assinalar mais de uma resposta se necessário)". Dentre as opções de respostas estavam: "Verbal (cantadas, ameaças, ofensas)", "Moral (ações humilhantes e constrangedoras feitas durante o trabalho)", "Sexual (ameaça, insinuação de ameaça ou hostilidade visando objetivos sexuais)" e "Não sofri assédio".
} 